\title{
Congenital \\ Abnormalities in \\ Production Animals
}

\author{
David L. Williams, MA, VetMB, PhD, CertVOphthal, CertWEL, FRCVS
}

\section{KEYWORDS}

- Ruminant • Congenital $\bullet$ Eye $\bullet$ Microphthalmia

The increase in number of food-producing animals raised each year implies that even small prevalences of congenital anomalies in these ruminant species are still reflected in a significant number of affected animals born each year. The problem for an ophthalmologist interested in such conditions is accessing these animals. Most animals with a spontaneous idiopathic condition present as a single case in a farm population and are normally euthanized and disposed of without even alerting the veterinarian responsible for the flock or herd, let alone a specialist in a referral institution situated at some distance from the farm. It takes a specific investigation, such as that of Hässig and colleagues ${ }^{1}$ into the association between congenital bovine cataract and electric power lines, to show the true incidence of such congenital abnormalities. Although insufficient, such studies are currently being undertaken to identify the true level of uncommon congenital ocular abnormalities. This article does not provide a complete overview of every congenital eye defect; such overviews are available in the key textbooks of the subject ${ }^{2,3}$ and indeed in Leipold's ${ }^{4}$ review in the previous issue of the Veterinary Clinics of North America on large animal ophthalmology. Rather, this article discusses recent research into several conditions to demonstrate the opportunities that exist for investigating such conditions both from a genetic and an environmental perspective.

\section{ANOPHTHALMOS AND MICROPHTHALMOS}

It might seem strange to begin the review of ocular abnormalities with anophthalmos, in which animals are born without eyes. And yet in truth, even when an orbit appears devoid of ocular tissue (Fig. 1), almost always a vestigial remnant of ocular tissue can be found; these are cases of extreme microphthalmos. A cattle breed in which anophthalmos is seen as a relatively common disorder is the Japanese brown cow. ${ }^{5}$ In this breed, animals are born with a remnant of pigmented tissue deep in the orbit and also with caudal sacral and tail abnormalities. In a study of 921 calves born with bilateral or

Department of Veterinary Medicine, University of Cambridge, Madingley Road, Cambridge CB3 OES, UK

E-mail address: doctordlwilliams@aol.com 


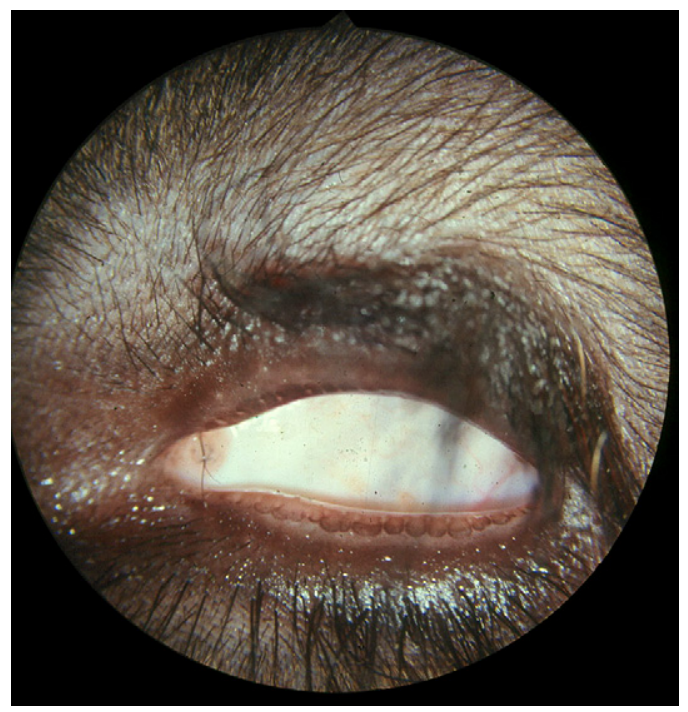

Fig. 1. The orbit of an anophthalmic calf.

unilateral apparent anophthalmos of 231,540 births (giving a prevalence of $0.39 \%$ ) the authors found that $21 \%$ of the animals lacked tail or had other severe sacral abnormalities (Fig. 2). In humans, this so-called anophthalmia-plus syndrome has been reported, ${ }^{6}$ but the embryologic link between globe development and caudal vertebral abnormalities is unclear. The orbit in any anophthalmic animal or human fails to develop normally because the normally enlarging globe regulates the development of the surrounding bony structures. Thus anophthalmic or severely microphthalmic animals have abnormally small orbits (Fig. 3).

It is known that genetic mutations of the homeobox pax 6 gene, the master control gene of the eye, ${ }^{7}$ lead to aniridia when in the heterozygous state and anophthalmos when homozygous. ${ }^{8}$ In fact, later work has shown a cascade of gene products necessary for normal globe development, with sine oculis and eyes absent activated by the eyeless gene product ${ }^{9}$ and vax 2 mediating the activation or inhibition of pax 6 , with sonic hedgehog modulating the position of the vax2 gene product in the nucleus or cytoplasm. ${ }^{10}$ With such a complex interaction of genes, it is not surprising that the



Fig. 2. The facial features of the calf are distorted by the abnormally small orbit. 


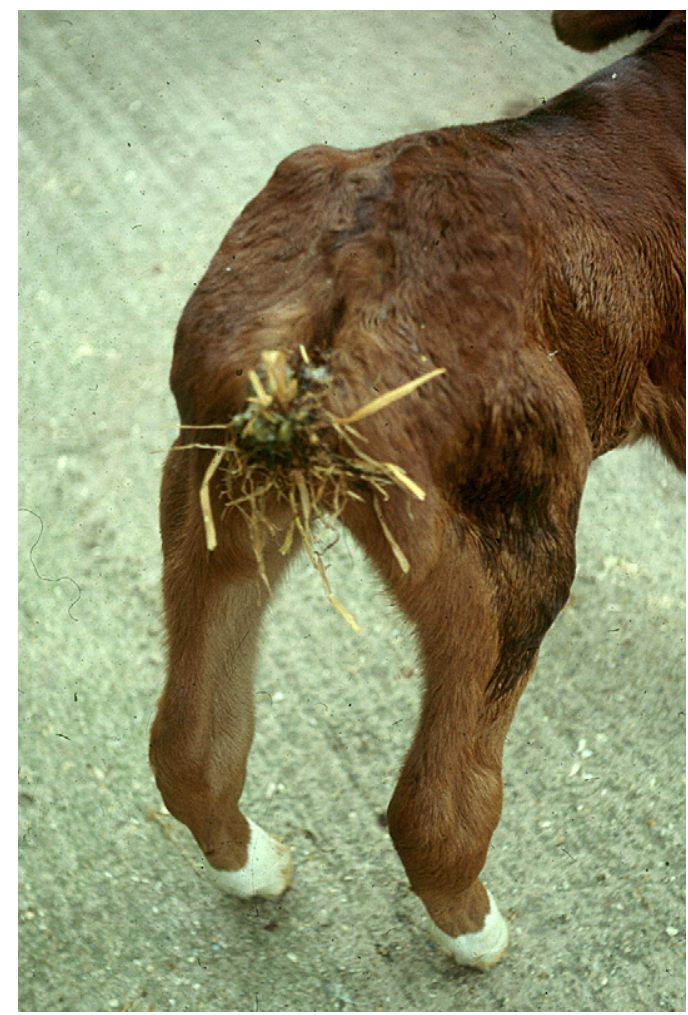

Fig. 3. Caudal vertebral abnormalities with lack of tail in this anophthalmic calf.

mutation responsible for anophthalmos in Japanese brown cattle or the sporadic cases seen rarely in the United Kingdom and Europe have not been identified.

Indeed, environmental factors may also play an important part. Vitamin A is essential not only in retinal function when the eye is fully developed but also in eye development itself, as described in later sections. ${ }^{11}$ Piglets born with hypovitaminosis $A$ have been reported to have abnormalities in globe development. ${ }^{12,13}$ Attempts were made to link the birth of clusters of offsprings with anophthalmos to the use of the fungicide benzimidazole (Benomyl), ${ }^{14}$ which can cause the developmental defect in rats. ${ }^{15}$ Indeed, this was the reason for the epidemiologic study in bovine anophthalmos by the author. Evidence is lacking for a link in humans or cattle.

Microphthalmos in sheep, manifested as clinical anophthalmos, with an apparently empty orbit (Fig. 4), was first noted in New Zealand ${ }^{16}$ and has since been intricately studied through a collaborative effort by researchers in Switzerland, Germany, and Australia. The condition occurs as an autosomal recessive trait and has been linked to a region on chromosome $23^{17}$ involving a missense mutation in the homeobox gene PITX3. ${ }^{18}$ Such detailed work allows the condition to be used as a model for similar pathologic condition in man.

\section{CYCLOPIA}

A well-recognized abnormality is cyclopia in the offspring of sheep feeding on the corn lily Veratrum californicum (Fig. 5). 


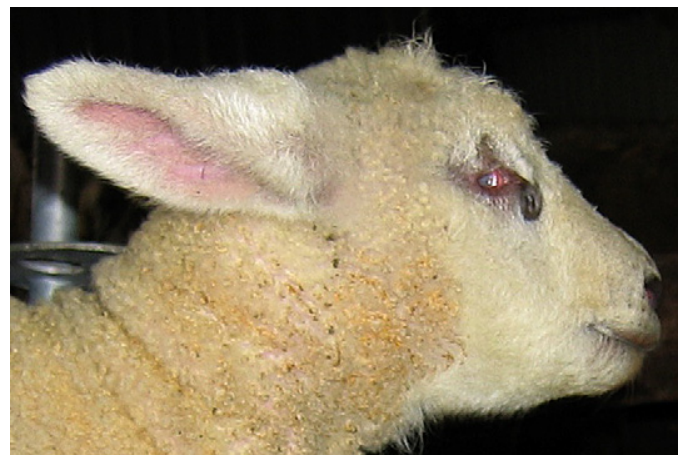

Fig. 4. Microphthalmic lamb with PITX3 mutation. (Courtesy of $\operatorname{Dr} C$. Drögemüller, Berne, Switzerland.)

The condition was first noted in Idaho in the late 1950s in sheep grazing in fields containing this plant. The development of cyclopia, in which one frontal eye exists (see Fig. 5), or synophthalmia, in which both eyes are joined in one frontal orbit (see Fig. 2A in the article by Middleton elsewhere in this issue), is part of a wide range of craniofacial abnormalities arising from the teratogenic action of the alkaloidal steroid cyclopamine, ${ }^{19,20}$ but with a relatively narrow window of activity, both temporally and dose-related. ${ }^{21}$ Cyclopamine inhibits the hedgehog signal transduction pathway. Mouse embryos cultured in the presence of cyclopamine to silence their sonic hedgehog gene show these changes of cyclopia and the associated developmental brain defect holoprosencephaly. ${ }^{22}$ Given that the sonic hedgehog gene is involved

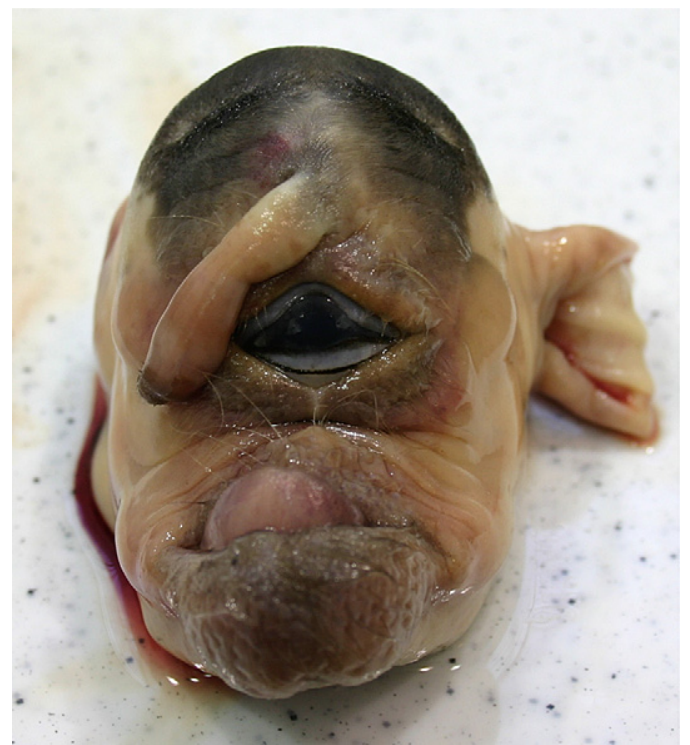

Fig. 5. A cyclopic lamb born by cesarean delivery at 135 days' gestation. Note the single central eye and the proboscis characteristic of such developmental defects. (Courtesy of Poisonous Plant Research Laboratory, Agricultural Research Service, United States Department of Agriculture, Logan, UT.) 
in several cancers, cyclopamine may be a valuable antineoplastic agent. ${ }^{23}$ The condition can be avoided by preventing pregnant sheep from ingesting the lilies. Whereas the teratogens produce craniofacial defects and microphthalmia in laboratory rodents, cyclopia is not a well-recognized consequence of administration. ${ }^{24}$

\section{MULTIPLE CONGENITAL ANOMALIES: GENETIC AND INFECTIOUS CAUSES}

A syndrome of iris and lens defects, microphthalmia, retained embryonic intraocular vasculature, and retinal dysplasia and detachment has been reported in cattle for nearly 40 years. ${ }^{25-27}$ But it is only in the last one year that the genetic mutation responsible for this apparently diverse set of lesions has been discovered. ${ }^{28}$ The WFDC gene on chromosome 18 encodes a small secretory protein, which acts as a protease inhibitor, and in Japanese black cattle with recessively inherited multiple congenital ocular defects, a frameshift mutation prematurely terminates gene expression. However, not all cattle have a recessively inherited trait, and linkage analysis has also shown a dominantly inherited gene mutation on chromosome 5, which accounts for the genetic heterogeneity of the condition. ${ }^{29}$

Other nongenetic etiologic factors can be associated with multiple congenital ocular defects. Of these, a key one is hypovitaminosis A during fetal development. In one report, microphthalmos, microcornea, aphakia, absence of iridal structures with retinal dysplasia, and a degree of optic nerve hypoplasia were noted in $25 \%$ of calves born to a group of suckler cows, which themselves showed signs of vitamin deficiency, such as blindness and papilledema. ${ }^{30} \mathrm{~A}$ more recent article from France reported that cows with similar signs and a similar history of maternal malnutrition produced calves with microphthalmia, aphakic globes with retinal dysplasia, and optic nerve hypoplasia. ${ }^{31}$

An important infectious cause of ocular deformities in cattle is the pestivirus bovine viral diarrhea. ${ }^{32}$ Retinitis resulting form viral infection leads to retinal dysplasia, ${ }^{33}$ whereas other defects can include cataract and more profound developmental globe abnormalities. ${ }^{34}$ Exposure of the dam to such infection between 125 to 175 days of gestation can lead to these ocular birth defects together with neurologic abnormalities, whereas exposure after 175 days typically leads to a healthy calf fully immune at birth. ${ }^{35}$

Another viral infection, emerging in the United Kingdom and Europe as a consequence of the northerly spread of the transmitting midges, is the orbivirus bluetongue. Although not causing globe defects, intrauterine infection of the developing calf or lamb by the virus can lead to hydrencephaly with complete lack of the cerebral hemispheres. ${ }^{36,37}$ These animals, while still having a pupillary light reflex, because their midbrain is still present and functioning, are behaviorally blind and are noted to be "dummy" calves. Profound corneal edema has also been reported in some calves infected in utero with bluetongue virus, ${ }^{38}$ although these calves were not affected by hydrencephaly (Fig. 6).

\section{CONGENITAL CATARACT}

Congenital cataracts have been documented in cattle in several reports, with the prevalence as high as $34 \%$ in some herds. ${ }^{39}$ In a large study in England undertaken as a doctoral study by Caroline Manser (née Cley), ${ }^{39} 3.7 \%$ of more than 800 calves were noted to have lens opacities (Fig. 7). While it was impossible to assign a specific cause to lens opacities, they were seen in calves born later in the summer months and were rarely seen in heifers. Cataracts linked to genetic defects generally include other ocular abnormalities such as retinal detachment, aniridia, microphakia, and 


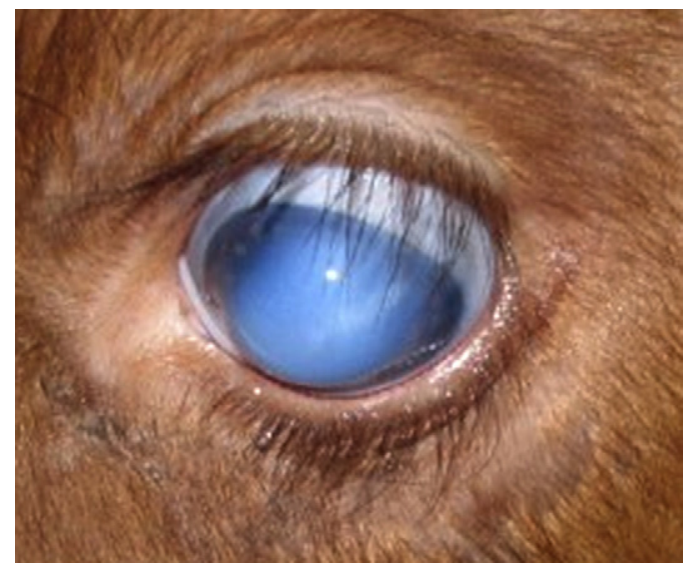

Fig. 6. Profound corneal edema in a calf infected with bluetongue virus.

hydrocephalus. As discussed earlier, microphthalmia and cataracts with retinal dysplasia have been documented in calves exposed to bovine viral diarrhea in utero.

Manser's doctoral studies were undertaken in the late 1970s, and since then little new work has been reported until last year when Hässig and colleagues ${ }^{1}$ published a study potentially linking nuclear cataract in Swiss veal calves with mobile telephone antennae. On 1 farm, a quarter of newborn calves had lens opacities. In a randomized study, slightly more than 250 veal calves from Swiss abattoirs were examined, their proximity of birth to mobile telephone base station antennae was determined, and samples were taken to evaluate signs of infectious agents, such as bovine viral diarrhea, Toxoplasma, and Neospora, and to document signs of oxidative stress. Oxidative stress is a key feature of many forms of cataract, with oxidation causing cross-linking of thiol groups of lens crystallins with subsequent protein aggregation and cataract formation. ${ }^{40,41}$ Of 156 male calves, $37 \%$ had cataract, whereas $25 \%$ of female calves showed lens opacities. The association between cataract and proximity to telephone mast and electromagnetic field strength was statistically significant, as was the association between cataract and intraocular oxidative stress as determined by the concentration of the protective antioxidant enzymes superoxide dismutase, catalase, and glutathione peroxidase. ${ }^{1}$ It remains for others to investigate the extent to which electromagnetic radiation from mobile telephone mast is associated



Fig. 7. Nuclear cataract. (Courtesy of Dr C. Manser (née Cley), Histon, Cambridge.) 


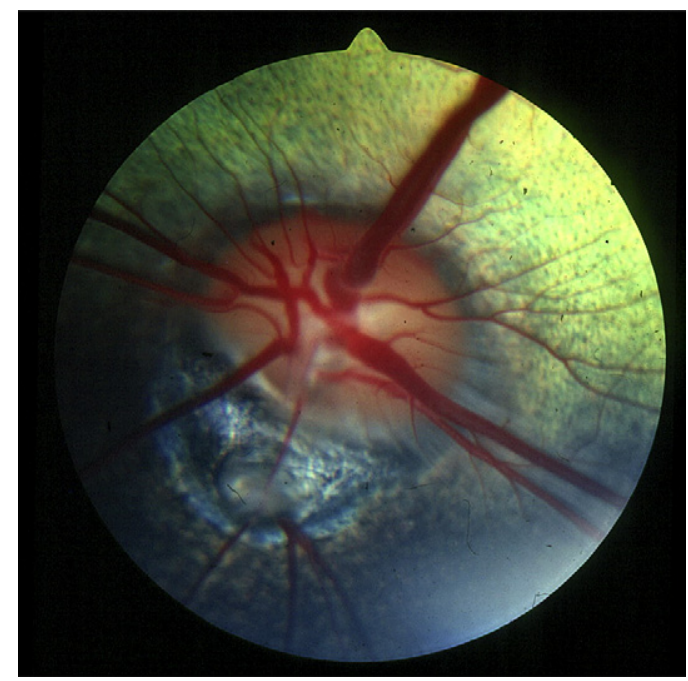

Fig. 8. A typical (ie, at 6-o'clock position) coloboma in a Charolais bull.

with nuclear cataracts in calves. Clearly, there must be other etiologic factors, mobile telephones were not in existence in the 1970s when Caroline Cley published her thesis, and anecdotal comments suggest that an association between marshy environments and these nuclear cataracts may exist (Scott D, personal communication, 2010).

\section{OPTIC NERVE COLOBOMAS}

Optic nerve coloboma (Fig. 8) was first described in Charolais cattle by Barnett and Ogien $^{42}$ in 1972 and subsequently reported by others also. ${ }^{43}$ The genetics of these lesions is somewhat curious: the autosomal dominant inheritance of the condition is completely penetrant in the bull but only incompletely penetrant $(52 \%)$ in the cow, whereas it is apparently recessive in F1 crossbred animals. ${ }^{44}$ The condition is still prevalent in the breed, with the author having seen several herds with significant numbers of animals affected, as might be expected in a dominantly inherited trait, but a condition not obvious unless the eye is specifically examined with an ophthalmoscope. Animals do not seem to be particularly affected with regard to their vision, although clear assessment of bovine visual acuity is not readily accomplished in a farm environment. Whereas developmental defects of the optic nerve in humans are often associated with other ocular signs related to failure of optic cup closure, ${ }^{45}$ neurologic abnormalities, ${ }^{46}$ or genetic systemic disorders, ${ }^{47}$ none of these seem to occur in these Charolais cattle. The colobomas are certainly associated with an abnormality in optic cup fissure closure, as demonstrated by their predominantly typical (ie ventral) appearance (see Fig. 8), but this occurs with the formation of a cystic defect, as often seen in optic nerve colobomas in other species. ${ }^{48,49}$

\section{SUMMARY}

The substantial volume of research into congenital defects in ruminants means that a review such as this can only skim the surface of the subject. Whole books could be written with an article for each condition. Indeed, this author has not touched on 
many interesting areas such as dermoids in cattle or ocular neoplasms seen at or shortly after birth. Nevertheless, it is hoped that the information presented in this article has shown the great advances that have been made in many areas, at least regarding the etiology and pathogenesis of several conditions since Leipold's ${ }^{4}$ review. Emerging diseases such as bluetongue need further work. Although Osburn's paper from $1972^{37}$ shows that this is hardly a new disease, it is just one newly presenting to us in the cold North as the world warms. Human interventions from Benomyl and its potential involvement with anophthalmos to mobile phone microwave radiation and bovine cataract are likely to expand in years to come and may render the field of congenital eye disease in farm animals even more important than it is at present.

\section{REFERENCES}

1. Hässig M, Jud F, Naegeli $H$, et al. Prevalence of nuclear cataract in Swiss veal calves and its possible association with mobile telephone antenna base stations. Schweiz Arch Tierheilkd 2009;151:471-8.

2. Townsend WM. Food and fiber-producing animal ophthalmology. In: Gelatt KN. Veterinary ophthalmology. 4th edition. Oxford (UK): Blackwell Publishing; 2007. p. 1275-335.

3. Lavach JD. Large animal ophthalmology. St Louis (MO): CV Mosby; 1990.

4. Leipold HW. Congenital ocular defects in food-producing animals. Vet Clin North Am Large Anim Pract 1984;6:577-95.

5. Moritomo Y, Koga O, Miyamoto $\mathrm{H}$, et al. Congenital anophthalmia with caudal vertebral anomalies in Japanese brown cattle. J Vet Med Sci 1995;57:693-6.

6. Makhoul IR, Soudack M, Kochavi O, et al. Anophthalmia-plus syndrome: a clinical report and review of the literature. Am J Med Genet A 2007;143:64-8.

7. Gehring WJ. The master control gene for morphogenesis and evolution of the eye. Genes Cells 1996;1:11-5.

8. Quiring R, Walldorf U, Kloter U, et al. Homology of the eyeless gene of Drosophila to the Small eye gene in mice and Aniridia in humans. Science 1994;265:785-9.

9. Halder G, Callaerts P, Flister S, et al. Eyeless initiates the expression of both sine oculis and eyes absent during Drosophila compound eye development. Development 1998;125:2181-91.

10. Kim JW, Lemke G. Hedgehog-regulated localization of Vax2 controls eye development. Genes Dev 2006;20:2833-47.

11. Cvekl A, Wang WL. Retinoic acid signaling in mammalian eye development. Exp Eye Res 2009;89:280-91.

12. Palludan $B$. The influence of vitamin A deficiency on foetal development in pigs with special reference to eye organogenesis. Int J Vitam Nutr Res 1976;46:223-5.

13. Darcel CL, Nilo L, Avery RJ, et al. Microphthalmia and macrophthalmia in piglets. J Pathol Bacteriol 1960;80:281-6.

14. Källén B, Robert E, Harris J. The descriptive epidemiology of anophthalmia and microphthalmia. Int J Epidemiol 1996;25(5):1009-16.

15. Hoogenboom ER, Ransdell JF, Ellis WG, et al. Effects on the fetal rat eye of maternal benomyl exposure and protein malnutrition. Curr Eye Res 1991;10: 601-12.

16. Roe WD, West DM, Walshe MT, et al. Microphthalmia in Texel lambs. N Z Vet J 2003;51:194-5.

17. Tetens J, Ganter M, Müller G, et al. Linkage mapping of ovine microphthalmia to chromosome 23, the sheep orthologue of human chromosome 18. Invest Ophthalmol Vis Sci 2007;48:3506-15. 
18. Becker D, Tetens J, Brunner A, et al. Microphthalmia in Texel sheep is associated with a missense mutation in the paired-like homeodomain 3 (PITX3) gene. PLoS One 2010;5:e8689.

19. Bryden MM, Evans HE, Keeler RF. Cyclopia in sheep caused by plant teratogens. J Anat 1971;110:507.

20. Keeler RF. Cyclopamine and related steroidal alkaloid teratogens: their occurrence, structural relationship, and biologic effects. Lipids 1978;13:708-15.

21. Welch KD, Panter KE, Lee ST, et al. Cyclopamine-induced synophthalmia in sheep: defining a critical window and toxicokinetic evaluation. J Appl Toxicol 2009;29:414-21.

22. Nagase $T$, Nagase $M$, Osumi $N$, et al. Craniofacial anomalies of the cultured mouse embryo induced by inhibition of sonic hedgehog signaling: an animal model of holoprosencephaly. J Craniofac Surg 2005;16:80-8.

23. Berman DM, Karhadkar SS, Hallahan AR, et al. Medulloblastoma growth inhibition by hedgehog pathway blockade. Science 2002;297:1559-61.

24. Keeler RF. Teratogenic effects of cyclopamine and jervine in rats, mice and hamsters. Proc Soc Exp Biol Med 1975;149:302-6.

25. Leipold HW, Gelatt KN, Huston K. Multiple ocular anomalies and hydrocephalus in grade beef Shorthorn cattle. Am J Vet Res 1971;32:1019-26.

26. Rupp GP, Knight AP. Congenital ocular defects in a crossbred beef herd. J Am Vet Med Assoc 1984;184:1149-50.

27. Kaswan RL, Collins LG, Blue JL, et al. Multiple hereditary ocular anomalies in a herd of cattle. J Am Vet Med Assoc 1987;191:97-9.

28. Abbasi AR, Khalaj M, Tsuji T, et al. A mutation of the WFDC1 gene is responsible for multiple ocular defects in cattle. Genomics 2009;94:55-62.

29. Ihara N, Fujita T, Shiga K, et al. Linkage analysis reveals two independent loci for ocular disorders in a local Japanese black cattle population. Anim Genet 2005; 36:132-4.

30. Mason CS, Buxton D, Gartside JF. Congenital ocular abnormalities in calves associated with maternal hypovitaminosis A. Vet Rec 2003;153:213-4.

31. Millemann $\mathrm{Y}$, Benoit-Valiergue H, Bonnin JP, et al. Ocular and cardiac malformations associated with maternal hypovitaminosis A in cattle. Vet Rec 2007;160: 441-3.

32. Bistner SI, Rubin LF, Saunders LZ. The ocular lesions of bovine viral diarrheamucosal disease. Pathol Vet 1970;7:275-86.

33. Brown TT, Bistner SI, de Lahunta A, et al. Pathogenetic studies of infection of the bovine fetus with bovine viral diarrhea virus. II. Ocular lesions. Vet Pathol 1975;12: 394-404.

34. Scott FW, Kahrs RF, De Lahunte A, et al. Virus induced congenital anomalies of the bovine fetus. I. Cerebellar degeneration (hypoplasia), ocular lesions and fetal mummification following experimental infection with bovine viral diarrheamucosal disease virus. Cornell Vet 1973;63:536-60.

35. Kahrs RF, Scott FW, de Lahunte A. Congenital cerebella hypoplasia and ocular defects in calves following bovine viral diarrhea-mucosal disease infection in pregnant cattle. J Am Vet Med Assoc 1970;156:1443-50.

36. Vercauteren G, Miry C, Vandenbussche F, et al. Bluetongue virus serotype 8associated congenital hydranencephaly in calves. Transbound Emerg Dis 2008;55:293-8.

37. Osburn BI. Animal model for human disease. Hydranencephaly, porencephaly, cerebral cysts, retinal dysplasia, CNS malformations. Animal model: bluetongue-vaccine-virus infection in fetal lambs. Am J Pathol 1972;67:211-4. 
38. Holzhauer M, Vos J. 'Blue eyes' in newborn calves associated with bluetongue infection. Vet Rec 2009;164:403-4.

39. Ashton, Barnett KC, Cley CE. Congenital nuclear cataracts in cattle. Vet Rec 1977;100:505-8.

40. Spector A. Oxidative stress-induced cataract: mechanism of action. FASEB J 1995;9:1173-82.

41. Truscott RJ. Age-related nuclear cataract-oxidation is the key. Exp Eye Res 2005; 80:709-25.

42. Barnett KC, Ogien AL. Ocular colobomata in Charolais cattle. Vet Rec 1972;91: 592.

43. McCormack J. Typical colobomas in Charolais bulls. Vet Med Small Anim Clin 1977;72:1626-8.

44. Falco M, Barnett KC. The inheritance of ocular colobomata in Charolais cattle. Vet Rec 1978;102:102-4.

45. Berk AT, Yaman A, Saatçi AO. Ocular and systemic findings associated with optic disc colobomas. J Pediatr Ophthalmol Strabismus 2003;40:272-8.

46. Golnik KC. Cavitary anomalies of the optic disc: neurologic significance. Curr Neurol Neurosci Rep 2008;8:409-13.

47. Jacobs M, Taylor D. The systemic and genetic significance of congenital optic disc anomalies. Eye (Lond) 1991;5:470-5.

48. Williams DL, Barnett KC. Bilateral optic disc colobomas and microphthalmos in a thoroughbred horse. Vet Rec 1993;132:101-3.

49. Doughty MJ, Sivak JG. Scanning electron microscope evaluation of the corneal endothelium in a case of unilateral microphthalmos with retrobulbar cyst in the pigmented rabbit. Cornea 1993;12:341-7. 